\title{
INVESTIGACIÓN/RESEARCH
}

\section{GESTIÓN DE LA COMUNICACIÓN EN EL SECTOR NO LUCRATIVO ESPAÑOL}

María Jesús Fernández Torres ${ }^{1}$ : Profesora Universidad de Málaga. España. mariajesusfernandez@uma.es

\section{RESUMEN}

La sociedad actual se caracteriza por la existencia de tres sectores básicos: el sector público, el sector privado y el sector no lucrativo, denominado también Tercer Sector. El Tercer Sector es un concepto heterogéneo, de difícil acepción. Está compuesto por entidades que no tienen el lucro como principal objetivo, abarcando principalmente, dos grandes ramas: las entidades de economía social y las entidades no lucrativas. El problema estriba en que dichas entidades son percibidas de manera difusa como consecuencia de su falta de transparencia $y$, en muchas ocasiones, de su deficiente gestión de la comunicación. Dentro de las entidades no lucrativas se encuentran las Organizaciones no Gubernamentales que son autónomas e independientes del ámbito de los gobiernos sin fines lucrativos y que destinan sus recursos a financiar proyectos que emprenden en el ámbito de la cooperación al desarrollo, a solucionar los crecientes problemas de equidad, pobreza, exclusión social y destrucción ambiental, entre otros. Esta investigación tiene como objeto valorar el campo de la Economía Social y la gestión de la comunicación como herramienta estratégica. La buena gestión de la comunicación servirá para que estas entidades logren el apoyo público para una actividad, causa, movimiento o institución, consiguiendo de tal modo los fines y objetivos que se proponen.

PALABRAS CLAVE: Economía Social - Comunicación - Imagen - ONG

\footnotetext{
${ }^{1}$ Autor correspondiente.

María Jesús Fernández Torres. Facultad de Ciencias de la Comunicación de la Universidad de Málaga. España.

Correo: mariajesusfernandez@uma.es
} 


\title{
COMMUNICATION MANAGEMENT IN SPANISH NON-PROFIT SECTOR
}

\begin{abstract}
Today's society is characterized by the existence of three sectors: the public sector, the private sector and the nonprofit sector, also called Third Sector. The third sector is a heterogeneous concept, difficult to sense. It consists of entities that do not have profit as the main objective, covering mainly two major branches: the social economy entities and nonprofits. The problem is that these entities are seen diffusely due to its lack of transparency and, in many cases, poor management of its communication. Among the nonprofits are NGO that are autonomous and independent of the level of governments and nonprofit devoted its resources to finance projects undertaken in the field of development cooperation, to solve the growing problems of equity, poverty, social exclusion and environmental destruction, among others. This research aims to assess the field of Social Economy and communication management as a strategic tool. Good management of communication for these entities will achieve public support for an activity, cause, movement or institution, thereby achieving the goals and objectives proposed.
\end{abstract}

KEYWORDS: Social Economy - Communication - Image - NGO

\section{INTRODUCCIÓN}

El sector público, el sector privado y el sector no lucrativo son los tres sectores básicos de la sociedad. El Tercer Sector es un término de difícil acepción aunque en la mayoría de las definiciones se subraya el hecho de que está compuesto por entidades que no tienen el lucro como fin principal, abarcando dos grandes ramas: por una parte, las entidades de economía social (cooperativas, mutualidades...) y las entidades no lucrativas (asociaciones, fundaciones...). La legitimidad de las entidades que integran este Tercer Sector se han puesto en entredicho en numerosas ocasiones por diversos escándalos acontecidos en su seno. La falta de transparencia en muchas de estas entidades así como la deficiente gestión de comunicación que llevan a cabo, son problemas que dificultan la consecución de los objetivos que persiguen. Por tanto, es necesario generar acciones de comunicación que incentiven la adhesión de afiliados, voluntarios... 


\section{OBJETIVOS Y METODOLOGÍA}

Esta comunicación tiene como principales objetivos conceptualizar el sector de la Economía Social, conocer los pilares básicos sobre los que se fundamenta su razón de ser y sus actividades, valorar el impacto económico que supone en la sociedad actual esta parcela y considerar la importancia de la comunicación como herramienta estratégica que les lleva a conseguir los fines y objetivos propuestos.

La metodología utilizada se ha basado en el análisis de diferentes fuentes documentales y es descriptiva, teniendo como elemento básico la observación.

\section{ANÁLISIS Y DISCUSIÓN \\ 3.1 Economía social: Conceptualización.}

Sector No Lucrativo, Tercer Sector, Sector Voluntario y Economía Social; diferentes términos para una misma realidad.

El término Sector No Lucrativo, vinculado a lo anglosajón, es afín a una interpretación de la sociedad civil y comprende aquellas organizaciones en donde no existe una redistribución de beneficios entre sus miembros. El término Economía Social, vinculado a lo francés, pone el énfasis en aspectos socioeconómicos y destaca el compromiso de sus asociados. El término Tercer Sector, hace referencia al conjunto de organizaciones que proceden de la iniciativa privada pero orientada al interés general y sin ánimo de lucro. El Sector Voluntario subraya la labor de la prestación personal de servicios sin retribución económica a las organizaciones del Tercer Sector, principalmente de acción social.

De los términos mencionados, el más generalizado es el de Tercer Sector, al posicionarse entre el sector público y el sector privado. Pero la utilización de éste no ha suprimido el uso de los demás términos recurriéndose a los mismos cuando quieren destacarse determinados aspectos de una misma realidad: el interés general, la solidaridad, la responsabilidad social y la participación ciudadana.

Existen multitud de definiciones sobre Economía Social. Así, la definición consensuada por la Unión Europea es la que entiende la economía social como: "La actividad económica ejercida por un conjunto de entidades privadas las cuales, mediante una gestión democrática, aúnan los valores de participación, responsabilidad y solidaridad con los de rentabilidad y eficacia para desarrollar un régimen de propiedad y de distribución de ganancias que favorece el crecimiento de la empresa, aumenta la producción de bienes y servicios y mejora los servicios a los socios y a las sociedades. Estas empresas que surgen en el mercado con la finalidad de crear riqueza, generar trabajo o de resolver problemas sociales"'.

En Francia, la "Charte de l'économie sociale" define el término como "El conjunto de entidades no pertenecientes al sector público que, con funcionamiento y gestión

\footnotetext{
${ }^{2}$ Federación Canaria de Desarrollo Rural, Canarias Rural 1, "Manual práctico de emprendeduría en economía social", en www.redcanariarural.org
} 
democráticos e igualdad de derechos y deberes de los socios, practican un régimen especial de propiedad y distribución de las ganancias, empleando los excedentes del ejercicio para el crecimiento de la entidad y mejora de los servicios a la comunidad".

He escogido otra definición expuesta en un estudio comparativo de la Universidad Hopkins de Baltimore (Ruiz Olabuénaga, J.I., 2000), en donde se exponen cinco criterios clave que determinan los rasgos básicos que debe poseer una institución cualquiera para poder ser entendida como parte del Tercer Sector:

- Estar organizada formalmente: Lo que supone una realidad institucionalizada, con estructuración interna. Criterio que excluye las manifestaciones informales de solidaridad, colaboración y ayuda mutua.

- Ser privada: Ello implica que debe estar separada institucionalmente del Gobierno y por tanto, no estar controlado por éste. Sin embargo, ello no significa que la organización no pueda recibir apoyo público ni excluye que pueda haber funcionariado público en sus órganos de gobierno.

- Ausencia de ánimo de lucro: No debiendo repartir beneficios entre sus propietarios, administradores o directivos. Por tanto, los beneficios que obtengan deben ser reinvertidos en función de la misión corporativa de la organización.

- Disfrutar de la capacidad de autocontrol institucional de sus propias actividades: Las organizaciones del Tercer Sector deben tener sus propios mecanismos de autogobierno y han de gozar de autonomía.

- Alto grado de participación voluntaria: La participación de sus miembros no dependerá de imposiciones externas sino de la libre voluntad de los mismos.

Pero es en la Ley 5/2011, de 29 de Marzo, de Economía Social, donde se establece por primera vez un marco de referencia y una definición legal de la Economía Social. Esta Ley se aprueba debido a diferentes iniciativas destacables. Por un lado, la demanda de la Confederación Empresarial Española de la Economía Social (CEPES) y, por otra, los trabajos realizados por la Subcomisión Parlamentaria del Congreso de los Diputados y cuyo objetivo era el estudio de la situación de la economía social en España y proponer actuaciones para su fomento. Así, el Gobierno, por medio del Consejo para el Fomento de la Economía Social y con el acuerdo de CEPES, designó una Comisión independiente de personas expertas que, en Octubre de 2009, finalizó los trabajos de elaboración de estudio de una Ley de Economía Social. El objetivo básico de esta Ley era configurar un marco jurídico que supusiera el reconocimiento y mejor visibilidad de la economía social, estableciéndose los principios que deben contemplar las distintas entidades que la forman.

Es en el artículo 2 donde se define la economía social como "el conjunto de las actividades económicas y empresariales, que en el ámbito privado llevan a cabo aquellas entidades que, de conformidad con los principios recogidos en el artículo 4, persiguen bien el interés colectivo de sus integrantes, bien el interés general económico o social, o ambos". La definición nos lleva al artículo 4 sobre los principios orientadores de las entidades de economía social, a saber: 
a) Primacía de las personas y del fin social sobre el capital, que se concreta en gestión autónoma y transparente, democrática y participativa, que lleva a priorizar la toma de decisiones más en función de las personas y sus aportaciones de trabajo y servicios prestados a la entidad o en función del fin social, que en relación a sus aportaciones al capital social.

b) Aplicación de los resultados obtenidos de la actividad económica principalmente en función del trabajo y servicio aportado o actividad realizada por los socios o por sus miembros.

c) Promoción de la solidaridad interna y con la sociedad que favorezca el compromiso con el desarrollo local, la igualdad de oportunidades entre hombres y mujeres, la cohesión social, la inserción de personas en riesgo de exclusión social, la generación de empleo estable y de calidad, la conciliación de la vida personal, familiar y laboral y la sostenibilidad.

d) Independencia respecto a los poderes públicos.

\subsubsection{Actores de la Economía Social.}

En el marco de esta Ley, forman parte de la economía social, las cooperativas, las mutualidades, las fundaciones y las asociaciones que lleven a cabo actividad económica, las sociedades laborales, las empresas de inserción, los centros especiales de empleo, las cofradías de pescadores, las sociedades agrarias de transformación y las entidades singulares creadas por normas específicas que se rijan por los principio antes citados.

Podrán, a su vez, formar parte de la economía social aquellas entidades que realicen actividad económica y empresarial, cuyas reglas de funcionamiento respondan a los principios enumerados en el artículo anterior y que sean incluidas en el catálogo de entidades, realizado por el Ministerio de Trabajo e Inmigración en coordinación con las Comunidades Autónomas. Estos catálogos deben ser públicos.

Pasaré ahora, a dar una breve definición de cada uno de los actores que forman parte de la economía social:

- Cooperativas $\rightarrow$ Sociedades formadas por personas que se asocian para la realización de actividades empresariales con estructura y funcionamiento democrático. Esas actividades deben atender a los principios cooperativos: la adhesión voluntaria y abierta de los socios, la gestión democrática, la participación económica de los socios, la educación, formación e información y el interés por la comunidad.

- Mutualidades $\rightarrow$ Sociedades de personas, sin ánimo de lucro, de estructura y gestión democrática, que ejercen una actividad aseguradora de carácter voluntario y cuya finalidad es complementar las prestaciones básicas de la Seguridad Social de sus miembros o proteger sus bienes contra circunstancias de carácter fortuito.

- Fundaciones $\rightarrow$ Organizaciones constituidas sin fin de lucro. Están dotadas de un patrimonio propio otorgado por sus fundadores que contribuye a la 
realización de fines de interés general que, por voluntad de sus creadores, tienen afectado de modo duradero su patrimonio a la realización de fines de interés general.

- Asociaciones $\rightarrow$ Unión voluntaria de personas o de grupos en torno a un objetivo común. En este sector, se incluyen, sobre todo, las vinculadas a la discapacidad y a la inserción de personas en exclusión. Se centran en prestar servicios allí dónde el sector lucrativo falla en su provisión, que además suele coincidir con aquellos sectores en los que se satisfacen derechos fundamentales, sobre todo en su acceso a colectivos especialmente vulnerables.

- Sociedades laborales $\rightarrow$ Empresas cuyo capital social pertenece, en su mayoría, a los trabajadores que la conforman. En España, los trabajadores han de participar con, al menos, el $51 \%$ del capital social y ningún socio-trabajador puede tener más de $1 / 3$ del capital social.

- Empresas de inserción $\rightarrow$ Sociedades cuyo objeto social tengan como fin la integración y formación sociolaboral de personas en situación de exclusión social como tránsito al empleo. En su plantilla debe tener un porcentaje de trabajadores en inserción (dependiendo de cada Comunidad Autónoma) que oscilará entre el $30 \%$ y el $60 \%$. El $80 \%$ de los resultados se reinvierte en la empresa.

- Centros especiales de empleo $\rightarrow$ Entidades cuyo objetivo principal es realizar un trabajo productivo y compatibilizar la viabilidad económica y su participación en el mercado con su compromiso social hacia colectivos con menores oportunidades en el mercado de trabajo. Su finalidad es asegurar un empleo remunerado y la prestación de servicios de ajuste personal y social que requieren las personas con discapacidad que trabajan en el mismo (rehabilitación, terapéuticos, de integración social, cultural y deportivos...). Su plantilla está constituida por el mayor número de personas con discapacidad (cuyo número no puede ser inferior al $70 \%$ respecto al total de trabajadores). Desarrollan una capacidad competitiva y productiva que les permite introducir sus productos en el mercado.

- Cofradías de pescadores $\rightarrow$ Corporaciones de derecho público sectoriales, sin ánimo de lucro, representativa de intereses económicos de armadores de buques de pesca y de trabajadores del sector extractivo, que actúan como órganos de consulta y colaboración de las administraciones competentes en materia de pesca marítima y de ordenación del sector pesquero, cuya gestión se desarrolla con el fin de satisfacer las necesidades e intereses de sus socios, con el compromiso de contribuir al desarrollo local, la cohesión social y la sostenibilidad.

- Sociedades agrarias de transformación $\rightarrow$ Sociedades civiles de finalidad económico-social en orden a la producción, transformación y comercialización de productos agrícolas ganaderos, forestales, la realización de mejoras en el medio rural, promoción y desarrollo agrario y la prestación de servicios comunes que sirvan a aquella finalidad. 


\subsubsection{Impacto económico de la Economía Social en España.}

Según el estudio "Las grandes cifras de la Economía Social en España"3, realizado por el Centro Internacional de Investigación e Información sobre la Economía Pública, Social y Cooperativa (CIRIEC), con el apoyo del Ministerio de Trabajo e Inmigración y la Fundación ONCE, la Economía Social genera en la actualidad el $10 \%$ del Producto Interior Bruto (PIB) y da trabajo en España a más de dos millones de personas (algo más del $10 \%$ de la población ocupada).

Las instituciones de la economía social en España cuentan con más de 200.000 organizaciones. Cooperativas, Sociedades Laborales, Mutuas, Cofradías de pescadores, Fundaciones y Asociaciones forman parte de la economía social, también llamada Tercer Sector, un motor económico que supone el $10 \%$ del PIB español con una facturación de 116.000 millones de euros en 2008. Estos datos reflejan el gran peso que poseen las empresas que conforman este sector.

El estudio también pone de manifiesto que en España existen 152.000 asociaciones activas, de las que 27.000 son de acción social (que operan en el ámbito de la exclusión social) con un volumen de gasto de cerca de 13.500 millones de euros. Respecto a las fundaciones, el número total supera las 8.000 , entre las que 1.600 son de acción social.

El sector empresarial de la Economía Social suma 45.000 empresas que ofrecen empleos directos a 700.000 personas y facturan un montante superior a los 87.000 millones de euros. Destacar en este punto el grupo Mondragón, al que pertenece Eroski, la cooperativa más grande del mundo, con 33.714 puestos de trabajo, según los datos del estudio ${ }^{4}$.

Andalucía se encuentra a la cabeza del ranking nacional y el sector de Economía Social supone el $13 \%$ del PIB. Según declaraciones del presidente de la Junta de Andalucía ${ }^{5}$, José Antonio Griñán, en esta Comunidad Autónoma, hay 110.000 empresas cooperativas que crean 90.000 empleos directos. Asimismo, señala que 8 de cada 10 pueblos andaluces tienen una cooperativa o una sociedad.

Las tres mayores organizaciones del Tercer Sector Social en la actualidad en España son: La Organización Nacional de Ciegos de España (ONCE), Cáritas y La Cruz Roja Española. Estas tres entidades destacan por su envergadura y su configuración jurídica.

\footnotetext{
3 "La Economía Social factura el 10\% del PIB", Diario Expansión (23-02-2011).

4 "La economía social se consolida y supone el 10\% del PIB y del empleo en España", RTVE (22-022011).

5 Declaraciones del Presidente de la Junta de Andalucía en una conferencia organizado por la Confederación Empresarial Española de la Economía Social (CEPES) en Madrid el día 19-10-2011.
} 


\subsection{Imagen y comunicación de las empresas de Economía Social.}

La pregunta que cabe plantearse llegados a este punto es la siguiente: ¿de qué forma la población percibe el conjunto de organizaciones que conforman el Tercer Sector? ¿Por qué, en su mayoría, la proyección social de las imágenes de las mismas se asocia a un tratamiento "indigno" de las víctimas o de sus actores, que cuestiona su razón de ser?

Philip Kotler y Gerald Zaltman (1971) lanzaron una pregunta en una de sus investigaciones del Marketing Social, pregunta que, en mi opinión, sigue sin encontrar respuesta: "¿por qué no podemos vender fraternidad como se vende detergente?". En efecto, nos encontramos dos tipos de comunicación publicitaria: Una, la que habla de bienes de consumo y nos transporta a mundos de ficción aunque al alcance de nuestras manos y que lleva implícita una promesa de felicidad $y$, otra, la que habla de personas y no de bienes de consumo que describe una realidad dramática (remota) y que llevan implícita la idea de dolor, sufrimiento, injusticia y crudeza.

Por tanto, es evidente que una parte del problema de las estrategias comunicativas del Tercer Sector, se centra en su proyección social y es que nos encontramos ante empresas que son diferentes a cualquier empresa mercantil. Si las observamos desde el punto de vista económico, funcionan como una empresa tradicional pero su identidad social es lo que las diferencia del resto con valores tales como la ayuda mutua, la integración, la solidaridad, etc.

Pero la importancia de la comunicación en las empresas que conforman la Economía Social debe equipararse a la que tiene en cualquier otra organización. Sin embargo, "existe una opinión unánime que apunta a que las empresas de la Economía Social, no muestran sus proyectos, tienen una falta de iniciativa comunicativa, no tienen cultura de proyectar imagen y desconocen que esto puede influir en su negocio. En consecuencia, esto provoca que la comunicación, en muchos casos, no exista, sea endogámica, no sea transparente y sea reducida". (Herranz de la Casa y Salinas Ramos, 2004: 25).

Constituye, por tanto, un objetivo prioritario en este sector, la comunicación corporativa para fortalecer la imagen y la reputación.

Sanz de la Tajada (1994) afirma que son tres los elementos que rodean la comunicación empresarial:

- Dimensión IDENTIDAD: Analiza con mayor profundidad lo que la empresa es y los valores que la caracterizan (cultura, valores, misión, ...).

- Dimensión COMUNICACIÓN: Representa lo que la empresa dice que es.

- Dimensión IMAGEN: Determina lo que los públicos creen que es la empresa.

Si la comunicación es deficiente, la imagen no se ajustaría a la realidad. Por ello, es necesaria la gestión eficaz de la comunicación para que se superen las imágenes distorsionadas y alcanzar una alta reputación, entendiendo como reputación la 
consolidación de la imagen a lo largo del tiempo con valores como la excelencia, el prestigio y la calidad.

En España existe un medidor de empresas, MERCO (Monitor Español de Reputación Corporativa) que presenta el ranking con las empresas con mejor reputación. Cabe destacar que en el último informe presentado en 2012, este medidor refleja como mejores empresas algunas de las pertenecientes al sector de la Economía Social: ONCE $\left(10^{\circ}\right)$, Mapfre $\left(17^{\circ}\right)$, Mutua Madrileña $\left(47^{\circ}\right) \ldots$

Es gracias a la comunicación corporativa, herramienta de dirección estratégica de carácter holístico, que estas empresas de Economía Social cuentan con un buen grado de reputación e imagen.

La Responsabilidad Social Corporativa ${ }^{6}$, tan de moda en nuestros días y convertida en un atractivo valor estratégico para muchas empresas que buscan con ella, cada vez más, un amplio reconocimiento y presencia mediática, no debe desvincularse de las empresas de Economía Social ya que éstas, en su propia identidad, la llevan inserta tanto con sus socios y trabajadores como con el entorno donde se desenvuelven. Sin embargo, no suelen resaltarlo.

\subsection{El caso de las ONG.}

Dentro de las entidades no lucrativas se encuentran las Organizaciones no Gubernamentales que son autónomas e independientes del ámbito de los gobiernos, cuyo fin no es el lucro y que destinan sus recursos a financiar proyectos que emprenden en el ámbito de la cooperación al desarrollo.

Como su propio nombre indica, uno de los aspectos a destacar de las ONG es su externalidad a las estancias estatales. Debido a ello, desarrollan bastantes mecanismos de autofinanciación que les permite alejarse del régimen de subvenciones y ayudas estatales que impliquen una ligera supeditación de las actividades que desarrollan a las los intereses y directrices públicas.

Según Granda y Luzt (1988: 18), las características más sobresalientes de las ONG más importantes de los países europeos a destacar son: su creciente participación en los recursos otorgados por el Estado, la multisectorialidad de los programas y proyectos que apoyan en el Tercer Mundo, su origen confesional (católica y protestante) o laico, su capacidad de aglutinarse en algunos países en grandes colectivos, su articulación con amplios sectores de la sociedad civil y su participación en la política de cooperación para el desarrollo con sus respectivos países.

Como señala Ortiz Vaamonde (2002), las ONG se caracterizan por: Tratarse de organizaciones privadas, no tener ánimo de lucro (pudiendo generar beneficios pero

\footnotetext{
${ }^{6}$ La Responsabilidad Social Corporativa entendida como el conjunto de acciones que ejecuta la empresa y que refleja una preocupación y comportamiento ético, social y medioambiental con el objetivo de beneficiar a todos los públicos que se relacionan con ésta (stakeholders).
} 
sin distribuirlos entre sus miembros sino destinarlos a sus fines), ser altruistas (toda la gestión se realiza de forma voluntaria), tener sus propios órganos de gobierno, su patrimonio está afectado permanentemente a la realización de sus fines sociales, el derecho dota al patrimonio de personalidad jurídica propia e independiente de su fundador, benefician a grupos genéricos de personas, la acción registral es fundamental para conseguir la personalidad jurídica.

Para las ONG, la comunicación es un instrumento de sensibilización y educación para el desarrollo así como esencial a la hora de captar y fidelizar a socios y voluntarios y llevar a cabo campañas de sensibilización, educación y formación.

Tal y como señala Villafañe (1993), la imagen de una organización debe estar basada como mínimo en tres hechos. En primer lugar, debe basarse en la propia realidad de la organización. El segundo, es que en la imagen generada han de prevalecer los puntos fuertes de las ONG. Ello implica una óptima gestión de la comunicación y de las relaciones externas con el fin de propiciar una adecuada y correcta imagen intencional. El tercer aspecto a destacar es que no se trata sólo de trabajar sobre la cultura, la identidad y la comunicación, sino que debe tenerse en cuenta el manejo de las áreas funcionales de la organización puesto que todas tienen una repercusión, directa o indirecta.

Uno de los objetivos de las ONG es llegar a la opinión pública por los mecanismos más rápidos y amplios, como es el caso de los mass media. Estas pretensiones se delimitan en una intencionalidad movilizadora de los individuos, acerca de la educación y sensibilización social sobre determinadas temáticas. Estas apariciones mediáticas facilitan la creación de una mayor sensibilización social hacia los problemas defendidos por estas organizaciones; además y como norma general la presencia en los medios supone un incremento en los donativos, que finalizan al desaparecer estas campañas de los medios.

Asimismo existe el consenso entre las diferentes ONG de combinar la acción en los países del Tercer Mundo con la sensibilización en los mismos.

Los medios más receptivos a insertar los mensajes de educación para el desarrollo son los periódicos, emisoras de radio y televisiones locales puesto que los grandes medios son más reacios ya que esta temática no da buenos ratios de audiencia. Ante tal panorama, las ONG publican boletines y memorias que sirven para mantener el contacto con sus asociados e informarles de las actividades que lleva a cabo la organización.

Vistas las dificultades que tienen para infiltrar su mensaje en los medios, las ONG recurren a otros mecanismos para contribuir a la educación para el desarrollo y para darse a conocer ante la opinión pública. El más frecuente es la organización de charlas y conferencias.

Otro recurso para la promoción de mensajes y la sensibilización popular es la celebración de fiestas y conciertos musicales. La organización de festivales para 
recaudar dinero en situaciones de emergencia se han hecho ya casi habituales cada vez que ocurre una tragedia.

Los medios juegan un papel fundamental en el momento de presentar unas ONG y hacer desaparecer otras del sistema informativo.

El esquema de la relación entre ONG y sistema comunicativo se manifiesta como un proceso cíclico y cerrado en continuo movimiento. Este método se inicia con un acontecimiento que, en ocasiones, debido a un hecho no esperado y novedoso, motiva la aparición de momentos de especial excepcionalidad, situación que hace necesaria, para poder solucionar el problema, una llamada masiva al público y a los poderes públicos a través de los medios de comunicación y que produce a menuda una respuesta general e inmediata que casi siempre finaliza con la solución del problema a corto plazo, que viene a ser un paréntesis informativo de la cuestión hasta que vuelve a suceder un hecho no esperado y novedoso, momento en que retorna a comenzar el proceso. Esto ha llevado en ocasiones a un extremismo excesivo, ofreciéndose imágenes y opiniones impactantes, que buscan más el corazón del público, en lugar de la reflexión y el razonamiento de las posibles soluciones.

Al igual que ocurre con las políticas comunicativas de cualquier empresa con fin de lucro, el análisis del entorno y del mercado en los que se ubica la ONG, es esencial para diseñar un plan estratégico de comunicación que permita crear, construir y mantener, intercambios y relaciones recíprocamente beneficiosas con un público objetivo determinado con el propósito de conseguir los objetivos organizacionales difundidos.

La consecución de los recursos financieros y humanos lleva a un clima de competencia y disputa entre el ecosistema de organizaciones que pueden llegar a introducir un clima de tensión y estrés en las entidades.

\section{BIBLIOGRAFÍA}

Granda Alva, G. y Lutz Herrera, O. (1988). Las organizaciones no gubernamentales en la cooperación al desarrollo. Madrid: CIDEAL.

Herranz de la Casa, J.M. y Salinas Ramos, F. (2004). La comunicación en el ámbito de la Economía Social. Universidad Católica de Ávila.

Kotler, P. y Zaltman, G. (1971). "Social Marketing: An Approach to Planned Social Change", Journal of Marketing, vol. 35, julio, pp. 3-12.

Ortiz Vaamonde, M.L. (2002). Fundaciones. Cien preguntas clave y sus respuestas. Madrid: Dykinson.

Ruiz Olabuénaga, José Ignacio (2000). El Sector No Lucrativo en España. Madrid: Fundación BBV, Documenta. 
Sanz de la Tajada, L.A. (1994). Integración de la identidad y la imagen de la empresa. Madrid: Esic Editorial.

Villafañe, J. (1993). Imagen positiva. Gestión estratégica de la imagen de las empresas. Madrid: Pirámide.

BOE ( disponible en: http://boe.es/boe/dias/2011/03/30/, consultado el 15/11/2011) Monitor Empresarial de Reputación Corporativa (disponible en:

http://www.merco.info/es/countries/4/rankings/2 , consultado el 10/11/2011)

Diario Expansión (disponible en:

http://www.expansion.com/2011/02/23/entorno/1298415652.html?a=08c662e0df022 00c5bda26b412677bcc\&t=1323355260 , consultado el 11/11/2011)

RTVE (disponible en: http://www.rtve.es/noticias/20110222/economia-socialconsolida-supone-del-pib-del-empleo/410266.shtml , consultado el 11/11/2011)

\section{María Jesús Fernández Torres}

Doctora en Ciencias de la Comunicación, con una tesis que versó sobre Movimientos Sociales y comunicación en ONG. Fue la Doctora más joven de España. Técnico Auxiliar en Protocolo. Especializada en Comunicación Interna y Externa. Funcionaria de carrera y profesora de la Universidad de Málaga. Autora del libro "Las Relaciones Públicas como gestión de la Comunicación en los Movimientos Sociales. Análisis de la estrategia comunicativa de las ONG en España". En su haber tiene artículos en libros y revistas científicas. Secretaria del Consejo de Redacción de la Revista Internacional de Relaciones Públicas. Ha impartido clases en programas de doctorados y Masters. Ha participado en grupos de investigación de la Junta de Andalucía y ha participado en proyectos y equipos de trabajo en diferentes Delegaciones de Educación de Andalucía y otras Comunidades Autónomas. Ha trabajado en la Agencia de Noticias Europa Press y ha sido responsable de la Asociación de Consumidores y Usuarios, Confederación ASGECO, en Andalucía. 